\title{
eDiscovery readiness at the Ministry of Transport and Communications in Botswana
}

\author{
Katlego Ncaagae \\ University of Botswana \\ ncaage@yahoo.com \\ Received: 13 November 2019 \\ Revised: 18 January 2020 \\ Accepted: 18 April 2020
}

\begin{abstract}
This article presents the findings of the study which sought to assess e-discovery readiness at the Ministry of Transport and Communications (MTC) in Botswana and make recommendations to improve the e-discovery process. The assessment adopted the Document Labs' (Doculabs) Discovery Maturity Curve to examine: the e-discovery process; policies, procedures, and guidelines of e-discovery; and information organisation. Both qualitative and quantitative data collection tools were used. Semi-structured interviews with the records manager and IT manager were carried out to gain an insight into the state of e-discovery at the MTC and to allow the participants to describe the phenomena. With regard to quantitative data, the respondents were selected from 56 staff members in the IT, records management and administrative division, as they deal with the management of records. Data was analysed thematically and presented according to the objectives of the study. The study established that MTC was not e-discovery ready as the components that determine success in e-discovery such as undefined e-discovery processes, lack of policies, procedures as well as guidelines that promote successful e-discovery and the lack of a data map were not there. It is recommended that to be successful in e-discovery, MTC needs to develop and implement policies, procedures and guidelines for e-discovery; e-records retention policy; and a data map.
\end{abstract}

Keywords: e-records, e-discovery, e-discovery readiness, Ministry of Transport and Communications, Botswana

\section{Introduction}

Historically, records existed in paper form and, today, records are also in electronic format due to the rapid advances in information and communications technologies (ICTs). ICTs have become powerful, accessible, and widespread. The spread has increased the effectiveness of governments as they are now able to provide citizen-centric services online and involve citizens in governance (World Economic Forum, 2015). The Government of Botswana is no exception as it embarked on the automation and integration of processes through e-government (MTC 2012). Consequently, the production of e-records is rapidly increasing in government ministries. This development had an impact on litigations because when requested in court, parties are required to produce electronic records relevant to the case. This process is known as "electronic discovery or e-discovery" (Phillips et al. 2014; Sedona Conference 2020). The Sedona Conference (2020) describes e- 


\section{Katlego Ncaagae}

discovery as the aspect of identifying, collecting and producing electronically stored information (ESI) in response to a request for production in a lawsuit or investigation.

A study of the challenges of e-discovery in South Africa indicated that the main obstacles to adopting e-discovery include issues such as preparedness, lack of knowledge and education amongst lawyers as well as their clients, high costs and expenses associated with e-discovery, and issues surrounding the responsibility for the collection of evidence and allocation of costs (Stander et al. 2015). In this regard, the study revealed that some respondents stated that in South Africa, most organisations did not know what data they have, where it is stored and protection available for that data. This suggests that most South African organisations are unprepared or unready for e-discovery. E-discovery readiness may be referred to as "proactive e-discovery" where processes are put in place beforehand to classify, organise, and manage (retain/delete) information so that when you have a discovery request, you can respond quickly, easily, and much cheaper (Talley n.d.). This can be established efficiently and effectively by assessing policies and procedures, records management and ICT practices and infrastructure. Therefore, to achieve e-discovery readiness, an organisation must adopt best information management practises and e-discovery practises. E-discovery readiness is vital as it reduces organisational risks and controls litigation costs (Curtis \& Mew 2008). In the United States of America (USA), legal sanction costs associated with failure to comply with the e-discovery law are lowered through e-discovery readiness by monitoring employee behaviour looking for potentially criminal testimonials or activities (Osterman Research Inc. 2012). Additionally, the readiness helps organisations to assess its risks before meeting with the opposing counsel (Talley n.d.).

In Botswana, the Electronic Records (Evidence) Act of 2014 denotes that if the relevant electronic information is not recovered, it is disqualified from evidence, so e-discovery readiness could reduce the cost of producing poor-quality information that may end up being disregarded in court (Parliament of Botswana 2014). Apart from cost reduction, e-discovery readiness facilitates proper records management practices within the organisation. Proper records management ensures that relevant information is retained, hence allowing effective storage and disposal of records which reduce costs and potential risks by clearing out unnecessary, duplicative and outdated information (Miller \& Kelly 2015). Besides, e-discovery readiness will ensure that the time and resources an organisation invests today to find the right balance of technology, people and processes to manage ESI, will pay dividends in the next matter (Townsend 2013).

MTC is an area of interest as it is mandated to drive the development and utilisation of ICTs and the facilitation of e-government (MTC 2011). Moreover, the MTC provides IT infrastructure for all government entities through the Department of Information Technology (DIT) which also plays an important role in e-discovery. Additionally, the MTC is often surrounded by corruption allegations regarding fraudulent issuing of driver' licences, permits and certificates (BOPA 2014; Gabz FM 2014; Piet 2011). These indicate that MTC needs e-discovery as it faces a greater chance of being required to provide the ESI as evidence. 


\section{Statement of the problem}

E-records and/or ESI is needed to maintain evidence of information about business activities and transactions. However, previous studies focused on e-records management (Kemoni 2009; Moloi \& Mutula 2007) and e-records readiness (Kalusopa \& Ngulube 2012; Moatlhodi 2015) but did not investigate the ability to produce e-records as evidence in civil or criminal matters. These studies assessed areas that needed to be improved for the success of e-records management and provided recommendations which will eventually contribute to the success of e-discovery. Another study conducted by Stander et al. (2015) in South Africa is different from this study because it focused on e-discovery and its challenges but omitted to examine e-discovery readiness. Hence the study on e-discovery at the MTC was important as it would contribute to knowledge.

\section{Objectives of the study}

The main objective of the study was to assess e-discovery readiness at the Ministry of Transport and Communications (MTC) using the E-Discovery Maturity Curve. The specific objectives of the study were to:

1. establish the e-discovery process adopted by the Ministry of Transport and Communications.

2. examine the policies, procedures, and guidelines of e-discovery at the Ministry of Transport and Communications.

3. determine how electronically stored information is organised at the Ministry of Transport and Communications.

4. make recommendations to improve the e-discovery process at the Ministry of Transport and Communications.

\section{Literature review}

E-discovery is the process of finding and producing ESI for litigations (AIIM 2016; Phillips et al. 2014; The Sedona Conference 2020). E-discovery is important as it facilitates proper records and information management practices (Phillips 2012; Muir \& Barton 2008). Proper records and information management practices mean creating a data map, putting in place classification of data as well as establishing retention and deletion policies. Consequently, information management technologies and practices support the e-discovery process by reducing the risks of lawsuits and the cost of storing unnecessary information (Government of Alberta 2011). Muir and Barton (2008) state that in addition to the implementation of proper records and information management practices, companies should have an e-discovery protocol that establishes the procedures for identifying, preserving, and collecting data when litigation is anticipated and create a clear discovery process. 
The Electronic Discovery Reference Model (EDRM) depicted in Figure 1 was developed as a standard guideline for the process of e-discovery (EDRM at Duke Law 2019). The EDRM framework is a conceptual standard designed to serve as guidance for gathering and assimilating ESI during the legal process. The model was developed to address the lack of standards and guidelines in the e-discovery industry (Zapproved LLC 2018). At its inception, the EDRM's first stage was the records management, which was later changed to Information Governance (IG) due to the increased volume of data (Callaghan 2020). According to Callaghan (2020), managing ESI is now about much more than simple records management; rather the management of unstructured data sources such as social media and enterprise collaboration platforms.

EDRM emphasises that the process of e-discovery begins with information governance. This involves how the information is managed in the organisation. The second step is determining or identifying where the information is located. Once crucial ESI has been identified, the next step is preserving that evidence for litigation by placing data on legal hold and collecting the information relevant to the case. Custodians are identified, more documentation is gathered then data is processed and analysed to weed out irrelevant content. Information technology narrows down the dataset, legal counsel reviews the information and shapes its response to the lawsuit (LiveOffice LLC 2010; Callaghan 2020). Opposing parties also exchange relevant ESI, as required, and if the matter goes to trial, the information is presented in court. The process may require several technologies, content repositories, discovery tools, and specialised legal review software as well as services through the input of relevant departments or employees. The arrows within the EDRM indicate a direction of flow, but also cycle backwards to earlier stages, thus reflects the iterative and recursive nature of e-discovery (Zapproved LLC 2018). 


\section{Electronic Discovery Reference Model}

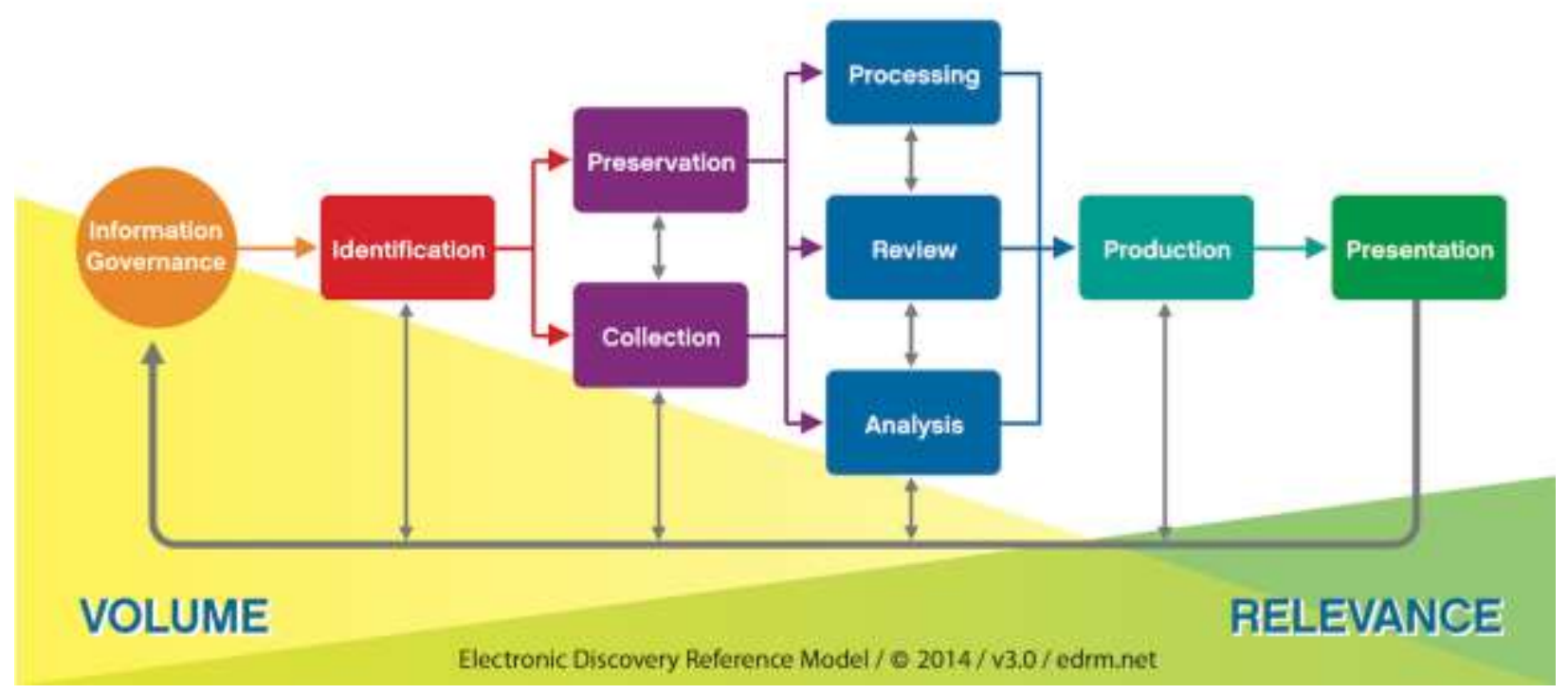

Figure 1: Electronic Discovery Reference Model (EDRM at Duke Law 2019; Callaghan 2020)

The EDRM is a guideline organisation could engage some, but not all, of the steps outlined in the model and still successfully discover relevant data. However empirical studies such as those by Ernst and Young (2013) and Deloitte \& Touche (2015) revealed that paper still plays an important role in most organisations, and ESI is printed for review, regardless of whether an electronic review system was used. As a result, converting documents to paper would not be considered providing them in searchable format thus the EDRM model could not be adopted by such organisations. However, the company that developed this framework (EDRM LLC) indicated that since its inception in 2005, it has had an international presence in 113 countries (EDRM LLC 2020). This suggests that the framework is a model of choice by some organisations around the world. Therefore, for this study, this framework was used in comparison to the e-discovery process the MTC has adopted. The comparison helped identify the gaps from the process adopted by MTC and recommendations were made according to the findings.

The discovery process is transforming, therefore organisations must develop a structure and processes to understand, manage and prepare for e-discovery through policies, procedures, and guidelines. Policies and procedures relating to the handling of ESI may affect whether and to what extent sanctions are imposed, especially if there is a corporate-wide understanding of the importance of preserving ESI (Sandill et al. 2012). However, Botswana does not have any specific law for e-discovery apart from the Act which was established for the admissibility and authentication of electronic information as evidence in legal proceedings (Parliament of Botswana 2014). The Act does not have a clause about the custodians of ESI's failure to comply, which 
implies that if the information is not recovered, it may be disqualified from evidence. This implies that Botswana does not have any guidelines or regulations for how organisations should carry out the process of e-discovery.

According to Bernard, Quartararo and Vinokur (2012), a records management policy is a vital policy benefitting e-discovery by ensuring that only appropriate documents are retained. Therefore, a company that implements an effective user document-creation and -retention policy is in a better position to produce ESI in litigations and successfully avoid sanctions related to failure to comply with obligations (Jablonski \& Duffy 2012). Besides the records management policy, the organisation should also have a litigation hold policy in place. A litigation hold policy is an instruction within an organisation directing employees to refrain from destroying or modifying certain records and information that may be relevant to the subject matter of a pending or anticipated lawsuit or investigation (Fenton, Rabeh \& Shapiro 2011; Panarella \& Kim 2012). Arguably, in the absence of a litigation hold policy, a records management policy can be implemented to include a clause on destroying or modifying certain records relevant to the pending investigations.

The increased use of e-records made it more difficult for businesses to monitor records-retention policies, which becomes problematic if they fail to comply with the records-retention regulations or become involved in litigation (Luoma 2006). An empirical study by Symantec surveying legal representatives and IT professionals in 2,000 companies worldwide investigated whether organisations have information retention plans in place and found that most companies did not have any in place (Symantec 2011; Peacock 2011). However, the findings of another study indicated that companies in the US had a document retention policy (Kroll Ontrack Inc. 2010). This study sought to establish whether MTC implemented a records-retention policy.

The e-discovery process can be executed efficiently and effectively by an organisation that knows what information it has and where it is stored. This can be achieved through the establishment of an organisational ESI data map. A comprehensive and defensible ESI data map will increase an organisation's ability to manage preservation and collection effectively, thus reducing legal risks (Collins 2010). Moreover, it allows an organisation to make an informed judgement about the cost, burden, and scope of the potential discovery, and allows the legal team to determine where there may be a disconnect between stated policies and IT processes. As a result, the researcher wanted to determine the establishment of a data map at the MTC.

\section{Theoretical framework}

After reviewing the literature on e-discovery, it can be argued that there is no integrated framework for assessing e-discovery readiness. However, the models that are suitable to assess e-discovery readiness include the e-discovery maturity model, the discovery maturity curve (DMC) and the IRMT e-records readiness tool. The e-discovery maturity model documents the evolution of organisational e-discovery strategy used to respond to litigation or regulatory demands (Hurwitz 
2010). The DMC is used to evaluate discovery readiness against the necessary conditions for success (Doculabs 2009). IRMT's e-records readiness tool is used to determine whether e-records and information management integration is capable of supporting e-government initiative (IRMT 2004).

The e-discovery maturity model is used to assess the organisation's e-discovery maturity level by utilising the appropriate human resources and technology to achieve e-discovery. As a consequence, it was disqualified from being the model of choice because it did not address the objectives of this study. The DMC and IRMT e-records readiness tool have similar components, but the e-records readiness tool addresses records management (RM) practices in depth, whereas the DMC emphasises those aspects of RM critical to e-discovery. Since the IRMT e-records readiness tool is comprehensive to records management, it needs to be used in conjunction with ediscovery tools to ensure that each phase of the e-discovery process is incorporated.

Although an organisation that has fulfilled the components of the e-records readiness tool is in a better position to be e-discovery ready, the model selected to guide this study is the DMC, because it has additional components which encompass e-discovery and its inclusion in the Records and Information Management (RIM) lifecycle. Moreover, the model does not exclude other organisational functions in its key components. The adopted model assisted the researcher in determining whether the MTC had developed policies, procedures and standards of e-discovery, and a data map, and assessed how the process of e-discovery was carried out.

The key components of a sound discovery readiness programme of the DMC are the overall programme strategy, governance and operations, information organisation, process design and implementation, architecture and technology, and communication and training. However, for this article, three components (governance and operations, information organisation, and process design and implementation) are discussed. The components shown in Figure 2 are aligned to the objectives of the study. 
Key components of a sound discovery readiness programme

Governance and operations: emphasises that the governance structure is established, roles and responsibilities are defined, policies, procedures and guidelines are implemented.

* Information organisation: critical as it includes content taxonomy (how information is organised or classified), records-retention plan and ESI repository map (to show where the information is stored).

* Process design and implementation: involves the overall processes used to support discovery readiness and responses are addressed with the inclusion of discovery process (EDRM) and the records or information lifecycle management processes (Medina 2011).

Where is your organisation in the discovery maturity curve?

\begin{tabular}{|c|c|c|}
\hline Trailing & Majority & Leaders \\
\hline $\begin{array}{ll}\text { O } & \begin{array}{l}\text { Governance and } \\
\text { operational structure at } \\
\text { most partially developed }\end{array} \\
\text { Oules, policies, } \\
\text { procedures, guidelines- } \\
\text { at most partially } \\
\text { designed } \\
\text { No adequate taxonomy } \\
\text { and retention plan even } \\
\text { partially developed } \\
\text { No ESI repository map } \\
\text { even partially developed } \\
\text { Discovery processes not } \\
\text { evaluated or even } \\
\text { partially designed }\end{array}$ & $\begin{array}{l}\begin{array}{l}\text { Governance and operational } \\
\text { structure partially developed } \\
\text { or partially implemented }\end{array} \\
\text { Rules, policies, procedures, } \\
\text { guidelines - partially } \\
\text { designed, implemented or } \\
\text { practised }\end{array}$ & $\begin{array}{l}\begin{array}{l}\text { Governance and } \\
\text { operational structure } \\
\text { implemented and } \\
\text { operational }\end{array} \\
\text { Rules, policies, procedures, } \\
\text { guidelines-implemented } \\
\text { and practised } \\
\text { Developed and } \\
\text { implemented taxonomy } \\
\text { and retention plan with the } \\
\text { methodology for further } \\
\text { development and } \\
\text { maintenance } \\
\text { Developed ESI repository } \\
\text { map } \\
\text { Discovery processes } \\
\text { evaluated, designed, } \\
\text { implemented, monitored } \\
\text { and maintained }\end{array}$ \\
\hline
\end{tabular}

Figure 2: Discovery Maturity Curve (Doculabs 2009)

Figure 2 depicts that at each component of the DMC, the assessor decides whether the organisation can be categorised on the Trailing, Majority or Leaders. Those companies that fall under trailing lag behind in the processes of e-discovery and have not developed or implemented any strategies. The model suggests that most organisations are aware of e-discovery and have partially developed or implemented strategies related to e-discovery (Medina 2013). The leading companies in ediscovery have company overall strategy, policies, procedures and guidelines as well as retention plans developed and implemented (Doculabs 2009). Subsequently, it can be concluded that an 
organisation categorised as "leading" has met the necessary requirements needed to be e-discovery ready. A leading company is in a better position to provide ESI as evidence in civil or criminal matters than others as the model depicts. Therefore, the components shown in Figure 2 were tested at the MTC to determine whether MTC falls under "Trailing", "Majority" or "Leaders"; consequently, concluding whether MTC was e-discovery ready.

\section{Methodology}

This study used both quantitative and qualitative data collection instruments (Ayiro 2012). Data was collected using questionnaires and interviews. These instruments were used to validate one form of data with the other form and address different types of questions (Creswell \& Plano Clark 2007). The researcher carried out semi-structured interviews to gain an insight into the state of ediscovery at the MTC and to allow the participants to describe the phenomenon. In this regard, the records manager and IT manager were interviewed. With regard to quantitative data, the respondents were selected from the IT, records management and administrative staff, as they deal with the management of records. The administrative staff comprised the following units: corporate services, human resources: recruitment, industrial relations, operations, accounts, administrative accounts and procurement. These units consisted of 56 staff members. These staff members were sent questionnaires but only 40 were returned. Staff members from other units were excluded from this study. Data were analysed thematically as per the objectives of the study.

\section{Findings}

According to the records manager and the IT manager, electronic records at MTC are printed and filed with other paper records and reside in employee computers. This indicates that there are no centralised locations where electronic records are stored. Similarly, a study on e-discovery in Ireland showed that $77.00 \%$ of the organisations indicated that they printed the final production set to paper, regardless of whether an electronic review system was used (Ernst \& Young 2013). The respondents from the accounting unit and the IT manager asserted that payments captured electronically can be retrieved from Government Accounting and Budgeting System (GABS) but are also reprinted. This means that MTC will continue to incur increased costs of producing erecords and then having to maintain them physically. As a consequence, there is a possibility of records being misplaced, dispersed and disintegrated if not managed electronically. In that regard MTC will continue to lag behind and not be ready for e-discovery since there is lack of e-records management.

According to Harrison (2018), in South Africa most emails are printed posing a potential risk of inefficiency and could be costly. He also indicated that electronic documents are more evidentially reliable than printed formats because when capturing electronic documents in their native format, the metadata of that document is also captured; thus it can inform the user who created the document, when it was created or subsequently modified, who were included as recipients and 


\section{Katlego Ncaagae}

much more. This suggests that while MTC is printing e-records, it is becoming inefficient and it may lose the original documents' authenticity.

Furthermore, the implication is that future researchers may not be able to produce any tangible findings that can influence policymaking, yet ministries fail to implement the recommended strategies. This leads to duplicated efforts in research. Moreover, there is a vital need for policymakers to ensure policies are not just a debut and to continuously monitor whether policies are implemented effectively. This will help e-records to be managed effectively, thereby facilitating e-discovery.

\subsection{The process of e-discovery}

The e-discovery process is widely governed by EDRM, which was designed to help organisations manage the process of e-discovery from the initial stages of managing ESI through to its presentation. It was therefore important for this study to establish the e-discovery process adopted at the MTC.

In an interview, the records manager stated that e-discovery is still a fallacy because even the manual system of records keeping is very poor. On another note, he said, "when it comes to availing information for litigations, the Attorney General Chambers (AGC) sends a letter to the Ministry requesting for information, and the relevant unit locates the information and reprints it." He also indicated that the information is not validated by MTC and with paper records, they would even check Botswana National Archives and Records Service (BNARS) to locate the information they need. The findings showed that e-discovery at MTC is still a challenge despite being able to discover paper records. MTC does not have overall processes used to support e-discovery and the process of discovering information is facilitated by the AGC. When asked whether they are guided on how to go about collecting, processing, and producing ESI for evidence, the records manager indicated that the AGC does not provide such guidance. Consequently, this leaves MTC in a vulnerable state because the information is not authenticated and if faced with litigations involving e-records, failure to produce information could lead to loss of corporate reputation and lawsuits.

E-discovery is a very important legal process because it facilitates good decision-making within the organisation as it allows those charged with managing litigations and the overall organisation to have sufficient insight about what is happening in their organisation and it reduces the risks of loss of corporate reputation, lost revenue and embarrassment. A 2012 market research survey conducted in North American companies found that it was anticipated that in 2013 e-discovery will become more important and will remain just as important as specified by $54 \%$ and $45 \%$ of the respondents respectively (Osterman Research Inc. 2012). These findings suggested that MTC should also consider or prepare to move towards improving e-discovery to enjoy the benefits of being up to standard with e-discovery. 


\subsection{Policies, procedures and guidelines of e-discovery}

Botswana has established the Act to provide for the admissibility of e-records as evidence in court and ensure electronic records are not denied admissibility into evidence on the sole ground that they were classified as electronic records. Additionally, the Act emphasises that a person who seeks to admit an e-record in any legal proceedings as evidence has the burden of proving its authenticity and that evidence must follow legal proceedings. Therefore, the study aimed to assess policies, procedures and guidelines of e-discovery at the MTC.

This study revealed that since every electronic transaction classified as a record is printed out and filed as paper, there is limited guidance on e-discovery. Consequently, MTC does not provide any guidance on policies and procedures for availing electronic information for litigation purposes. Despite the challenge, the records manager highlighted that if the need arises for MTC to produce any form of electronic records to be used as evidence in court, it will be availed by the records management unit, as their primary responsibility is to facilitate the availability of any records needed, irrespective of format; but in reality, MTC can do so only with paper records. This implies that even though policies, procedures and guidelines on e-discovery have not been defined, MTC will have to comply with the law when necessary. These findings show how unprepared the MTC is as far as e-discovery is concerned and illustrates that perhaps efforts for the better management of e-records need to be improved, especially through the implementation of policies and procedures on their use or management.

The framework as discussed in section 5 hinted that the policies and procedures on how to manage information or facilitate IG in the organisation. The absence of policies and procedures in MTC affects IG, which in turn affects the e-discovery process. Subsequently, MTC is likely to have issues of mismanagement and disintegration of data. Since MTC does not have policies and procedures governing the retention and production of ESI, one implication it has in practice is that the employees do not know what constitutes an electronic record. Consequently, this affects the management of such information as the staff do not know how to manage it or what they are supposed to retain or delete.

Moreover, the International Organization for Standardization (ISO) published the first of four parts of an International "E-discovery Standard", known as ISO/IEC 27050-1, Information Technology - Security Techniques - Electronic Discovery - Part 1: Overview and Concepts. The standard seeks to harmonise terminology, describe core concepts, offer guidance in several key areas (e.g. e-discovery governance, processes, and readiness) and identify relevant requirements (Hibbard 2014). The ISO standard provides the overview and concepts key to e-discovery as well as general guidance on measures an organisation can undertake to handle e-discovery efficiently and to mitigate the risk and expense involved in grappling with ESI (ISO; IEC 2016). MTC can adopt this ISO standard as a guideline on how to establish a description of e-records and how to prepare for e-discovery. 
The gap identified that previous studies did not investigate the procedures, guidelines, or standards of e-discovery within organisations and what they have adopted. For example, studies on ediscovery was done by AIIM Market Intelligence (2010), Coe (2008), Ernst \& Young (2013) and Kroll Ontrack Inc (2010). This demonstrates that it is unknown what direction or guidance organisations are operating on, therefore, there is a need for further research in this area.

\subsection{Information organisation at the MTC}

According to literature discussed in sections 1 and 4 of this article, proper records and information management practices, such as creating a data map, putting in place classification of data and establishing retention and deletion policies, promote the process of e-discovery. A data map is an important must-have tool for an organisation to ensure they are in a better position to locate ESI. The findings revealed that MTC has not developed or implemented a data map. In an interview, the IT manager alleged that MTC did not have a data map or document containing information on the location, the custodians and the details on their storage, accessibility, associated retention policies and procedures. On another note, the IT manager stated that when an employee leaves the MTC, their computer is formatted, and nothing is retrieved from it; thus loss of information. The findings are worrisome because it shows how unknowledgeable with their data landscape MTC is, which can be problematic with locating information or even their devices.

A similar study by Kroll Ontrack Inc. (2010) revealed that $56 \%$ of the companies did not have or did not know if their organisation had an inventory of where all data is stored. Thirty-two per cent of respondents were not aware of whether their organisation possessed a data map. The DMC suggests that an organisation with the same findings as MTC with no data map is lagging in this component of e-discovery. Lee and Hamilton (2015) concur that an organisation that understands the data environment is likely to be more prepared to deal with e-discovery than waiting until the matter arises. MTC lacks a document outlining a company's information landscape, and this may hinder the legal hold process at MTC, in addition to the effective response to litigation and regulatory requests. The findings affect practices at MTC such that there is a lack of accurate, detailed and up-to-date information about the organisation's IT systems; therefore, it is difficult for the relevant staff to make informed decisions about the cost, burden and scope of ESI.

Furthermore, the study established that $64 \%(n=25)$ of the employees at MTC were not certain about the existence of a records-retention policy, while $23 \%(n=9)$ agreed that it existed. The minority of $13 \%(n=5)$ said it did not exist. In corroboration, it was confirmed during an interview that there was no records-retention policy at MTC, but there was a documented draft of the business classification for retention and the disposition of records that guide records management. The draft was not a working document and has been drafted for over two years. That indicated that MTC was more likely to lose valuable information and would fail to achieve acceptable legal compliance in e-discovery due to its lack of retention policy and ineffective practices. Howell and Cogar (2003:1) affirmed that an organisation cannot achieve acceptable e-discovery legal compliance without an appropriate and functioning records-retention programme. Moreover, MTC 
was at risk of retaining irrelevant information, hence increasing the cost of storage. These findings are important for MTC as they are a caution to the MTC to develop a retention policy, not only for e-discovery but also for other benefits such as minimising costs and retaining only records of value.

In a similar study by Symantec (2011) entitled "Information Retention and e-Discovery Survey Global Survey", the findings revealed that nearly half of the respondents (companies) did not have an information retention plan in place. Thirty per cent were only discussing how to do so, while $14 \%$ had no plan to. When these companies were asked why they did not have an information retention plan, $41 \%$ of the respondents indicated that they did not need it and $38 \%$ noted that it was too costly. The fact that MTC has only developed a draft is an indication that it could be categorised among those organisations who were only discussing how to do so. The DMC emphasises that an e-discovery-ready organisation must have a records-retention plan or policy in place. The model underscores that an organisation like MTC that has not implemented a recordsretention plan is lagging in this aspect of e-discovery.

However, the findings of another study indicated that $79 \%$ of companies in the US had a documentretention policy (Kroll Ontrack Inc, 2010). This result insinuates that organisations are beginning to view document-retention policy as a core function of the organisation and appreciate that it is key for litigation response and regulatory compliance. The findings are different from those of this study because in the US, more organisations are concerned with the financial impact a discovery misstep such as sanctions can have on their organisations. This calls for MTC to implement the retention policy to put itself in a better position to comply with the legal processes.

\section{Summary of findings}

This study was deductive, therefore the findings of the study are summarised according to the objectives and the framework of the study. The summary of the findings is depicted in Table 1.

\section{Table 1: Summary of findings}

\begin{tabular}{|c|c|c|}
\hline & \multicolumn{2}{|c|}{ Discovery maturity curve } \\
\hline The objective of the study & Components of e-discovery & Study findings \\
\hline $\begin{array}{l}\text { 1. To establish the e- } \\
\text { discovery process adopted } \\
\text { by MTC }\end{array}$ & $\begin{array}{l}\text { Process design } \& \\
\text { implementation }\end{array}$ & $\begin{array}{l}\text { Discovery processes were not even } \\
\text { partially designed or evaluated }\end{array}$ \\
\hline $\begin{array}{l}\text { 2. To examine the policies, } \\
\text { procedures and guidelines } \\
\text { for e-discovery at MTC }\end{array}$ & Governance \& operations & $\begin{array}{l}>\text { Drafted records-retention plan } \\
\text { Lack of procedures and guidelines } \\
\text { for e-discovery }\end{array}$ \\
\hline $\begin{array}{l}\text { 3. To determine how ESI is } \\
\text { organised at MTC }\end{array}$ & Information organisation & $>$ Lack of data map \\
\hline
\end{tabular}


Table 1 shows that the MTC has not developed or implemented the components necessary for the success of e-discovery. Hence, as discussed in the theoretical framework section, it was concluded that MTC is in the "Trailing" group, thus not e-discovery ready.

\section{Conclusion and recommendations}

The EDRM was discussed as a framework designed as a guideline for the process of e-discovery, but the study findings indicated that discovery processes at MTC were not even partially designed. The reason being that when ESI is requested for litigation, the unit possessing such information locates the information and reprints it. Furthermore, the study examined the policies, procedures and guidelines of e-discovery at the MTC. The findings showed that MTC does not have policies, procedures and guidelines on e-discovery, let alone discovery of paper records. A records-retention policy plays a critical role in e-discovery, conversely, MTC does not have such in place, regardless of the available records' format. The MTC only has a documented draft of the business classification for retention and disposition of records which has not been completed.

A data map is an important tool for an organisation to ensure it is in a better position to locate ESI, but the findings revealed that MTC has not developed or implemented a data map. This is attributed to the MTC's e-records residing in individual computers. In conclusion, the study has achieved its purpose of assessing the level of e-discovery readiness at the MTC. Based on the DMC, the study revealed that MTC is "not e-discovery ready" and does not meet the requirements for e-discovery. The findings revealed that the reasons for its lack of readiness were attributed to undefined ediscovery processes and the lack of policies, procedures and guidelines that promote successful ediscovery and the lack of a data map. The study recommends that:

I. MTC should develop as well as implement policies and guidelines necessary for or could benefit e-discovery through the guidance of Botswana National Archives and Records Services (BNARS). Moreover, MTC should

a. establish a data-retention policy and align it to the BNARS Records Management Procedure Manual to formalise rules for retaining and destroying electronic documents. The policy should establish the conditions and periods for which electronic information and records will be stored, retained, and destroyed after they are no longer active

b. adopt a suitable e-discovery standard as a guideline to provide the overview and concepts key to e-discovery as well as general guidance on measures the MTC can undertake to handle e-discovery efficiently.

II. MTC should develop and implement guidelines for its employees on collecting, processing and producing information for e-discovery through the guidance of the Attorney General Chambers. 
III. MTC should adopt e-discovery framework such as the EDRM as a step-by-step guideline for collecting, processing, and producing ESI. The EDRM would be the most suitable framework for MTC as it was designed to cater for both records and unstructured data sources.

\section{References}

AIIM Market Intelligence. 2010. E-discovery and ERM: how is records management performing in the new spotlight?

AIIM. 2016. What is e-discovery? http://www.aiim.org/What-is-eDiscovery (Accessed 1 September 2016).

Ayiro, L. 2012. A functional approach to educational research methods and statistics: qualitative, quantitative, and mixed methods approaches. Illustrated ed. Lewiston, New York: Edwin Mellen Press.

Bernard, J., Quartararo, M. \& Vinokur, J. 2012. E-discovery: tips for identifying and preserving ESI. http://www.stroock.com/siteFiles/Pub1233.pdf (Accessed 5 September 2016).

BOPA. 2014. PDPs a must - Molefhi. http://www.dailynews.gov.bw/news-details.php?nid=11884 (Accessed 25 August 2016).

Brownstone, R. 2009. E-discovery best practices: policies, protocols and preservation of electronically stored information.

http://www.fenwick.com/fenwickdocuments/ediscovery_policies_protocols_preservation. pdf (Accessed 23 March 2017).

Callaghan, P. 2020a. What Is the EDRM (Electronic Discovery Reference Model)? https://blog.pagefreezer.com/what-is-ediscovery-reference-model-edrm (Accessed 14 April 2020).

Callaghan, P. 2020b. What Is the Information Governance Reference Model (IGRM)? https://blog.pagefreezer.com/what-is-the-information-governance-reference-model-igrm (Accessed 14 April 2020).

Coe, E. 2008. Legal, IT groups collaborate on e-discovery: Survey. https://www.law360.com/articles/63201/legal-it-groups-collaborate-on-e-discovery-survey (Accessed 14 June 2017).

Collins, J.P. 2010. The ESI data map: an in-depth review. http://theingersollfirm.com/yahoo_site_admin/assets/docs/The_ESI_Data_Map_An_InDepth_Review.152121657.pdf (Accessed 27 March 2017).

Creswell, J. \& Plano Clark, V.L. 2007. Designing and conducting mixed methods research. Thousand Oaks: Sage.

Curtis, W.B. \& Mew, C.M. 2008. Preparing for e-discovery. https://www..edu/general_counsel/legal_topics/documents/PreparingforE-Discovery.pdf

(Accessed 8 September 2015).

Deloitte \& Touche. 2015. GCC e-discovery survey: How ready are you?

Doculabs. 2009. Managing information for e-discovery readiness. Document Labs.

EDRM at Duke Law. 2019. EDRM Model. 
https://www.edrm.net/wp content/uploads/2019/05/EDRM_Poster_36x24_May-2019.jpg (Accessed 10 October 2019).

EDRM LLC, 2005-2015. EDRM stages. http://www.edrm.net/resources/edrm-stages-explained (Accessed 28 September 2015).

EDRM LLC, 2020. Empowering the global leaders of eDiscovery. Available: https://www.edrm.net/ (Accessed 11 April 2020).

Ernst \& Young, 2013. E-discovery survey findings. Ireland: Ernst \& Young.

Fenton, E.S., Rabeh, D. \& Shapiro, J.M. 2011. Avoiding an electronic discovery disaster with litigation holds. Spring 18(3): 9-12.

Fitzgerald, J. \& Coppola, D.P. 2014. Taming the chaos of e-discovery with workflows, project management and technology.

http://www.kmworld.com/Articles/Editorial/ViewPoints/Taming-the-Chaos-of-E-

Discovery-with-Workflows-Project-Management-and-Technology-97361.aspx (Accessed 27 March 2017).

Friedman, K. 2017. Why the world is talking about e-discovery. http://pdf.dlapiper.com/pdfrenderer.svc/v1/ABCpdf9/GetRenderedPdfByUrl//Why\%20th e $\% 20$ world $\% 20$ is $\% 20$ talking\%20about $\% 20 \mathrm{e} \% 20$ discovery.pdf/?url=https://www.dlapipe r.com: $443 \% 2$ fen $\% 2$ fus $\% 2$ finsights $\% 2$ fpublications $\% 2$ f $2017 \% 2$ f01\%2fwhy-the-world-istalking-about-e-disco (Accessed 23 March 2017).

Gabz, FM. 2014. DCEC investigating over 100 corruption cases at Roads Dept. http://www.gabzfm.com/dcec-investigating-over-100-corruption-cases-roads-dept (Accessed 25 August 2016).

Government of Alberta, 2011. Litigation readiness and information management. http://www.im.gov.ab.ca/documents/imtopics/Litigation_Readiness_and_IM_Tip_Sht_1.p df (Accessed 1 September 2016).

Harrison, T. 2018. Bringing advancing technology in litigation - time to explore electronic discovery. http://www.derebus.org.za/bringing-advancing-technology-in-litigation-timeto-explore-electronic-discovery/07 (Accessed April 2020).

Hibbard, E. 2014. Electronic discovery standardisation. http://avemarialaw-law-review.avemarialaw.edu/Content/articles/v12i2.Hibbard.pdf (Accessed 23 March 2017).

Howell, C.T. 2009. The new importance of records retention and legal compliance. http://www.piledrivers.org/files/0632c0ef-814f-465a-b8b6-dd80ea20c5d9--694f77db4460-4865-9c33-0b3be5de79f6/legal-q4-2009-lr.pdf (Accessed 23 March 2017).

Howell, R.T. \& Cogar, R.N. 2003. Record retention and destruction current best practices. http://apps.americanbar.org/buslaw/newsletter/0019/materials/recordretention.pdf (Accessed 23 March 2017).

Hurwitz, A. 2010. The e-discovery maturity model. http://www.edrm.net/papers/the-e-discoverymaturity-model/ (Accessed 20 June 2017).

IRMT. 2004. The e-records readiness tool.

http://www.nationalarchives.gov.uk/rmcas/documentation/eRecordsReadinessTool_v2_D ec2004.pdf (Accessed 1 February 2017). 
ISO; IEC, 2016. ISO/IEC 27050-1:2016. https://www.iso.org/obp/ui/\#iso:std:iso-iec:27050:-1:ed1:v1:en (Accessed 23 March 2017])

Jablonski, J. \& Duffy, P.J. 2012. Drafting an effective records management policy. http://www.goldbergsegalla.com/sites/default/files/uploads/JJJ_DRIForTheDefense_EDis covery_Feb2012.pdf (Accessed 10 October 2016])

Kalusopa, T. \& Ngulube, P. 2012a. Developing an e-record readiness framework for labour organisations in Botswana.

http://journals.sagepub.com/doi/pdf/10.1177/0266666912446209 (Accessed 5 May 2017).

Kalusopa, T. \& Ngulube, P. 2012b. Record management practices in labour organisations in Botswana. SA Journal of Information Management 14(1): 15.

Kemoni, H.N. 2009. Management of electronic records: review of empirical studies from the Eastern, Southern Africa Regional Branch of the International Council on Archives (ESARBICA) region. Records Management Journal 19(3): 190-203.

Kroll Ontrack Inc. 2010. Fourth annual ESI trends report. https://www.krollontrack.com/library/esitrends4_krollontrack2010.pdf (Accessed 14 June 2017).

Lee, E. \& Hamilton, M. 2015. Five ways attorneys can optimise their company's e-discovery process.

http://www.stollberne.com/LegalTechBlog/wp-

content/uploads/2015/04/5_Ways_Attorneys_Can_Optimize_Their_E_Discovery_Proces s.pdf (Accessed 5 May 2017).

LiveOffice LLC. 2010. The IT manager's indispensable guide to e-discovery. California: LiveOffice.

Luoma, V.M. 2006. Computer forensics and electronic discovery: the new management challenge. Computers and Security 25(2): 91-96.

Medina, R. 2013. How to develop and implement your discovery readiness program. http://www.cmswire.com/cms/information-management/how-to-develop-and-implementyour-discovery-readiness-program-020464.php (Accessed 16 September 2015).

Miller, D.R. \& Kelly, B. 2015. E-discovery in 2015: will you feel the earth move under your feet? http://www.ediscoverylaw.com/files/2015/01/E-Discovery-in-2015.pdf (Accessed 23 March 2016].

Moatlhodi, T. 2015. An assessment of e-records readiness at the Ministry of Labour and Home Affairs in Botswana.

http://www.academia.edu/12146478/AN_ASSESSMENT_OF_ERECORDS_READINESS_AT_THE_MINISTRY_OF_LABOUR_AND_HOME_AFFA IRS_IN_BOTSWANA (Accessed 29 August 2016).

Moloi, J. \& Mutula, S. 2007. E-records management in an e-government setting in Botswana. Information Development 23(4): 290-306.

MTC. 2011. Ministry of Transport and Communications. http://www.gov.bw/en/Ministries--Authorities/Ministries/Ministry-of-Transport-andCommunications/About-MCST/ (Accessed 25 August 2016).

MTC. 2012. Botswana national e-government strategy 2011-2016. 
http://www.researchictafrica.net/countries/botswana/Nationa_e-

Government_Strategy_2011-2016.pdf (Accessed 25 September 2017).

Muir, C. \& Barton, C.I. 2008. Corporate strategies for reducing e-discovery costs.

Osterman Research Inc. 2008. The growing importance of e-discovery on your business. Washington: Osterman Research.

Osterman Research Inc. 2012. Key issues in e-discovery. Washington: Osterman Research.

Panarella, N. \& Kim, W. 2012. Implementing a litigation hold.

http://www.kelleydrye.com/publications/articles/1580/_res/id=Files/index=0/PLC_Implem enting (Accessed 10 October 2016).

Parliament of Botswana, 2014. Electronic Records (Evidence) Act, Gaborone: Botswana Government Gazette.

Peacock, M. 2011. Information retention includes more than just email, Symantec Survey Finds. https://www.cmswire.com/cms/information-management/information-retention-includesmore-than-just-email-symantec-survey-finds-012655.php (Accessed 11 April 2020).

Phillips, A., Godfrey, R., Steuart, C. \& Brown, C. 2014. E-discovery: an introduction to digital evidence.

https://books.google.co.bw/books?id=iJ-eAwAAQBAJ\&printsec=frontcover\&dq=e-

discovery+an+introduction+to+digital+

evidence \&hl=en\&sa=X\&ved=0ahUKEwjwstX2tNboAhURVRUIHXcPCaIQ6AEIJjAA\# $\mathrm{v}=$ onepage $\& \mathrm{q} \& \mathrm{f}=$ false $($ Accessed 7 April 2020).

Phillips, J.T. 2012. Implementing litigation readiness principles and practices. Available: http://www.armaedfoundation.org/pdfs/Implementing_Litigation_Readiness_AIEF_Rese arch_Report_Final_v26.pdf (Accessed 1 September 2016).

Piet, B. 2011. Ramsden confirms corruption at DRTS. http://www.mmegi.bw/index.php?sid=1\&aid=1795\&dir=2011/March/Friday18 (Accessed 25 August 2016).

Sandill, K., Strahan, M.K. \& Trenaman, L. 2012. The essentials of e-discovery (top five). https://www.andrewskurth.com/insights-880.html (Accessed 10 October 2016).

Stander, A., Hughes, K. \& Hooper, V. 2015. E-discovery in South Africa and the challenges it faces. http://ieeexplore.ieee.org/stamp/stamp.jsp?arnumber=7435507 (Accessed 23 September 2016).

Symantec, 2011. Information retention and e-discovery survey. Symantec.

Talley, U. n.d. Proactive eDiscovery: the key to reducing litigation risks and costs. http://www.ittoday.info/Articles/Proactive_eDiscovery.htm (Accessed 11 April 2020).

The Sedona Conference. 2020. The Sedona Conference glossary: ediscovery \& digital information management, Fifth. The Sedona Conference Journal 21(5): 303.

Townsend, K. 2013. Litigation readiness: best practices for managing e-discovery. http://www.kilpatricktownsend.com/en/Knowledge_Center/Publications/Articles/2013/04 /Litigation_Readiness_Best_Practices_for_Managing_eDiscovery.aspx (Accessed 10 September 2015).

World Economic Forum. 2015. The global information technology report. (Accessed 23 August 2016).http://www3.weforum.org/docs/WEF_Global_IT_Report_2015.pdf 


\section{Katlego Ncaagae}

Zapproved LLC. 2018. What Is the EDRM? https://zapproved.com/blog/what-is-the-edrm/ (Accessed 14 April 2020). 